\title{
Experimental Performance of Solar Receivers Designed to Use Oil as a Heat Transfer Fluid
}

\author{
J. S. P. Mlatho \\ Physics Department, Chancellor College, University of Malawi, P.O. Box 280, Zomba, Malawi \\ Correspondence should be addressed to J.S. P. Mlatho, stanmlatho@gmail.com
}

Received 27 June 2011; Accepted 1 August 2011

Academic Editors: R. S. Adhikari and P. Tsilingiris

Copyright () 2011 J. S. P. Mlatho. This is an open access article distributed under the Creative Commons Attribution License, which permits unrestricted use, distribution, and reproduction in any medium, provided the original work is properly cited.

A parabolic dish concentrator (PDC) has been designed to be used for charging a thermal energy storage (TES) that is for indirect cooking purpose. Three different receivers have been designed, fabricated, and their performance tested experimentally. The three designs are Volumetric Flask (VF), Volumetric Box (VB), and Conical Tube (CT) receivers. The receivers have been fabricated to use oil as a heat transfer fluid. Of the three designs, the CT receiver has the highest efficiency for a given flow rate, thus making it the best receiver. A positive displacement pump was also designed and constructed for the experimental tests. The pump is used to drive the oil through the receivers and also to act as a flow meter. Thus a low-cost and high-temperature positive displacement pump and a flow meter have been designed and fabricated for use in solar thermal studies.

\section{Introduction}

The aim of this work was to capture solar radiation and convert it into solar thermal energy for storage. The stored energy is to be used in an indirect solar cooker. The capture of solar radiation and conversion of it into solar thermal energy involves the use of solar receivers. In order to optimise these solar receivers, some studies have been carried out using computer models while others through experimental works [1-3]. A lot of research has been carried out on designing new receivers or improving the performance of existing ones $[4,5]$, and on understanding factors that affect their performance $[6,7]$. One group of these receivers is the volumetric solar receivers.

Volumetric receivers are generally used in central receiver solar power plants and have also been used for chemical applications [2], and the heat transfer fluid (HTF) used is usually air or any other suitable gas. The major advantage of volumetric receiver designs is the simplicity of their principle. Such receivers are suitable for use in rural households as they are simple and often reduce chances of hot spots developing within the receiver. Several studies have been carried out on volumetric solar receivers that use air as an HTF $[2,8,9]$. The use of wire mesh, ceramic absorbers, and other porous materials in these receivers has been observed to increase their efficiency [3, 9-13].

The literature review carried out does not indicate a large use of volumetric receivers in indirect solar cookers that have a separate solar collector and cooking unit or thermal energy storage (TES) system $[14,15]$. Moreover, these receivers have mainly been used with air as an HTF and metal foams as the porous media. Furthermore, most of the studies on metal foams have focussed on their pressure drop and flow characteristics. Among the studies that have focused on the thermal conductivity of these metal foams, very few have dealt with their characteristics under concentrated solar radiation (CSR) and using a liquid as the HTF. Thus there was a need to investigate the use of such porous materials in volumetric receivers for indirect solar cookers. In this study, heat transfer oil is used as the HTF and a wire mesh is used to improve the effective thermal conductivity and the flow of the oil in two of the three designed receivers. The wire mesh was chosen as the candidate for investigation because it is cheap and readily available to rural households in Africa. In this work, three receivers were designed and fabricated for use with an SK-14 parabolic dish reflector (PDR) [16] in order to make a PDC. The purpose of the PDC is to charge a TES system $[16,17]$ to be used in an indirect solar cooker. 


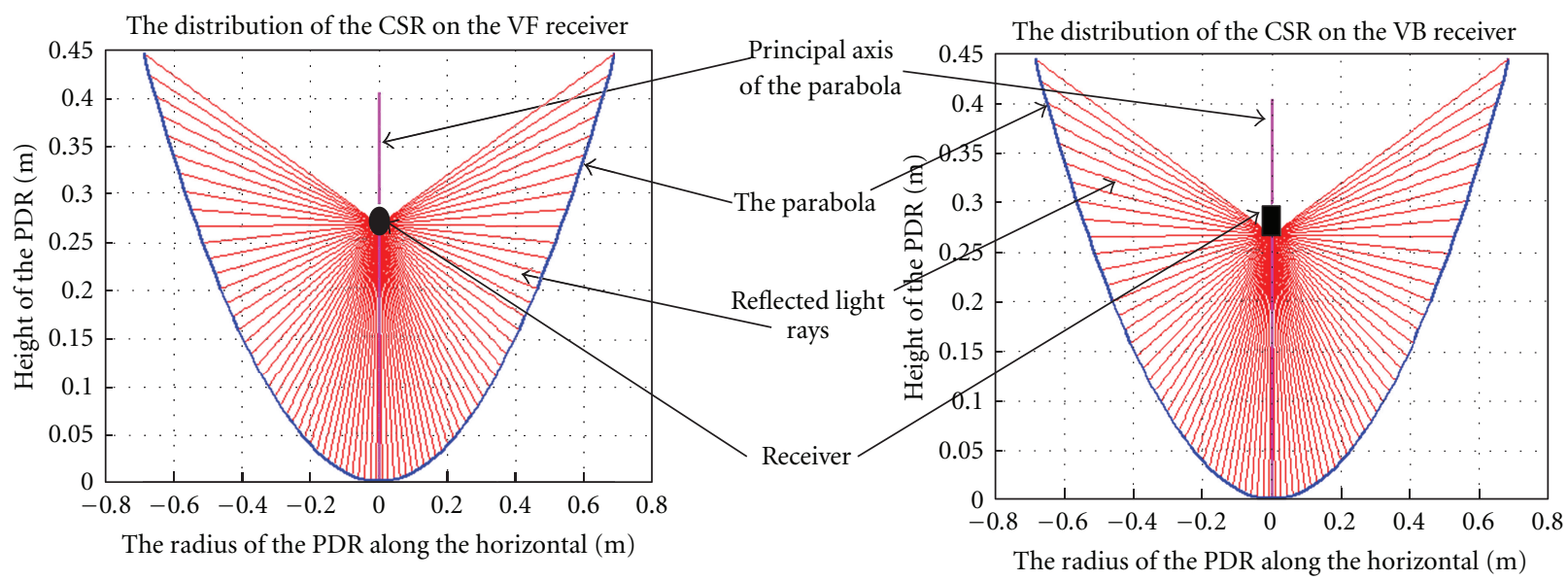

(a)

(b)

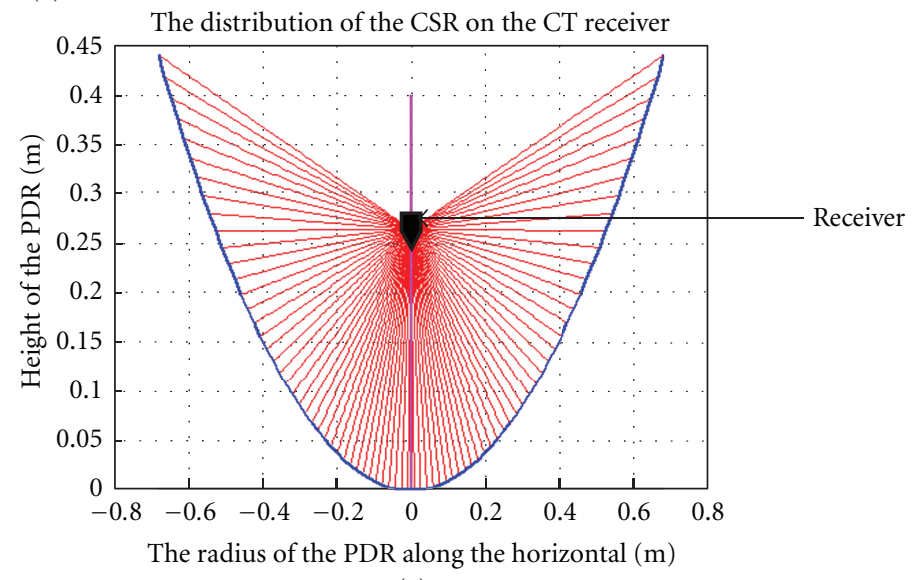

(c)

FIgURE 1: The CSR distribution at the apertures of the receivers placed at the FR of the SK-14 PDR obtained through ray tracing.

\section{Design and Description of the Receivers}

The shapes of the receivers, the surface shapes, and the diameter of the receiver apertures were chosen based on the work of reference [16] and also on the results of a raytracing program [17]. From the results of the spatial extent (SE) of the focal region (FR) obtained with a radiometer method [16], a diameter of $0.1 \mathrm{~m}$ for a flat aperture was considered as reasonable option in order to obtain maximum flux concentration. This is because the energy from the receivers is intended to be delivered at high temperatures of around $200^{\circ} \mathrm{C}$. Because the PDR has a large rim angle and is deep, the rays that reach its FR are not perpendicular to the focal plane. Instead, they arrive at angles of incidence that are greater than $0^{\circ}$.

From the results of the ray-tracing program, a receiver aperture with a parabolic surface is suitable for capturing the CSR at the FR of the PDR. For this reason, a volumetric receiver with a parabolic aperture surface was chosen as the first design. A laboratory glass flask with a round bottom and having a diameter of $0.1 \mathrm{~m}$ was modified into a receiver. This receiver is referred to as Volumetric Flask (VF) receiver. Figure 1(a) shows the rays of the direct solar radiation (DSR) reflected from the SK-14 PDR and incident onto the VF receiver that is placed at the FR of the PDR. The results of Figure 1 were obtained from the ray tracing of the SK-14 PDR [17]. As shown, a large percentage of the reflected rays fall onto the aperture surface area at angles of incidence that are nearer to $0^{\circ}$ and this is because of the parabolic shape of the aperture surface.

The VF receiver of Figure 2 is made of a round-bottom glass flask that is $500 \mathrm{~mL}$ in volume. Into the mouth of the flask is placed a silicon rubber stopper with two metal tubes that serve as inlet and outlet pipes for the oil. The inlet pipe is positioned at the centre of the flask and close to the aperture, and this reduces the radiative losses at the aperture since the oil flowing from the inlet cools it. A reflecting steel plate surrounds the flask from its neck to midway of the round bottom. The plate is insulated on the inside with a high-reflecting aluminium foil and on the outside with glass wool. This aluminium foil on the inside is for increasing the reflectance of the reflecting plate. The wool on the outside is then covered with the aluminium foil. The operation of the VF receiver depends on absorption of the CSR by the oil as well as on reflection of the CSR by the reflecting plate. The reflected CSR is eventually absorbed by the oil in the flask. As the oil flows from the inlet to the outlet, it continuously absorbs CSR. 


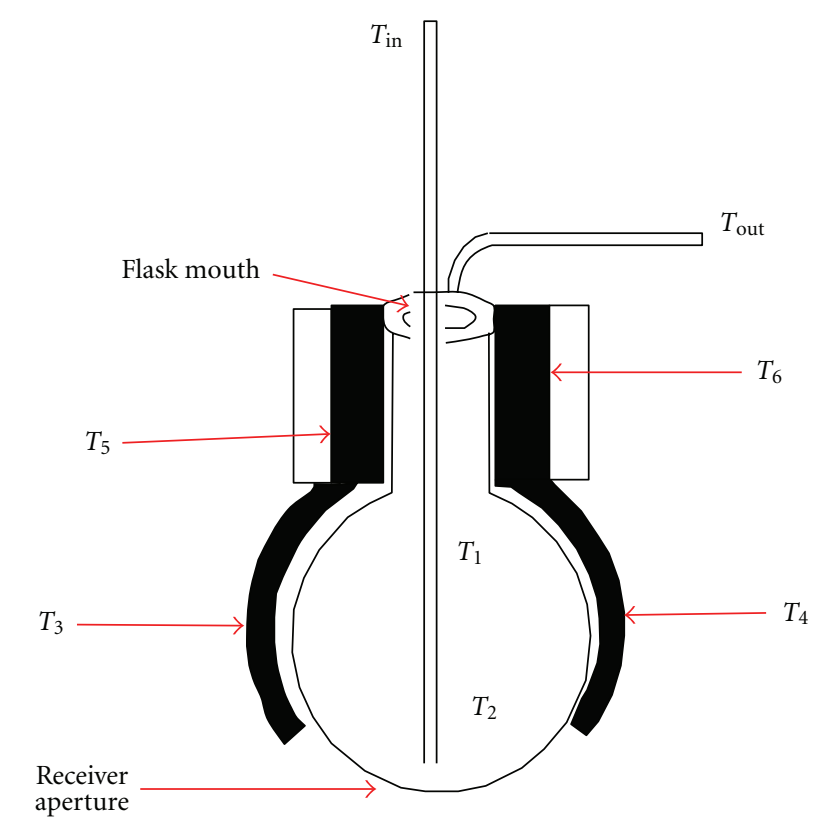

FIGURE 2: Schematic diagram of the VF receiver that also shows the locations of the thermocouples.

A second receiver design based on the results of the raytracing program is a cylindrical cavity receiver with a flat glass aperture. This receiver is referred to as Volumetric Box (VB) receiver. Figure 1(b) indicates that some of the reflected rays fall onto the cylindrical part of the $\mathrm{VB}$ receiver that is close to the aperture and this is because of the large rim angle of the PDR. The rays that fall onto the cylindrical cavity are those reflected from the PDR surface area that is close to its rim and represents a large percent of the CSR. Hence part of the cylindrical cavity that is close to the aperture should not be insulated so that it can receive the CSR from these PDR surface areas. The other implication is that, if the cylindrical part of this receiver is insulated, this would effectively reduce the effective surface area of the PDR that reflects the DSR to the receiver. For this reason, the section of the fabricated VB receiver close to its aperture was not insulated and was painted black so that it absorbed the CSR that fell on it.

This VB receiver of Figure 3 consists of a cylindrical cavity made of aluminium. It has inlet and outlet pipes at the back and an aperture of glass at the front. The inside of the receiver is left unpainted so that there is a high reflection of the incident CSR within the cavity. The outside of the cavity is painted black and partly insulated with glass wool. The glass wool is in turn covered with aluminium foil. The inlet is positioned close to the aperture so that its cool oil cools the aperture and thereby reduce radiative losses. The outlet pipe is at the back of the cylinder. Thus, oil flows in close to the aperture and flows out away from the aperture.

The third design is a metal receiver with a conical shape. This design arose because some of the reflected rays from the PDR surface area did not fall onto the aperture of the VB receiver. Figure $1(\mathrm{c})$ shows the distribution of the light rays on this receiver that is placed at the FR. The cone is placed at

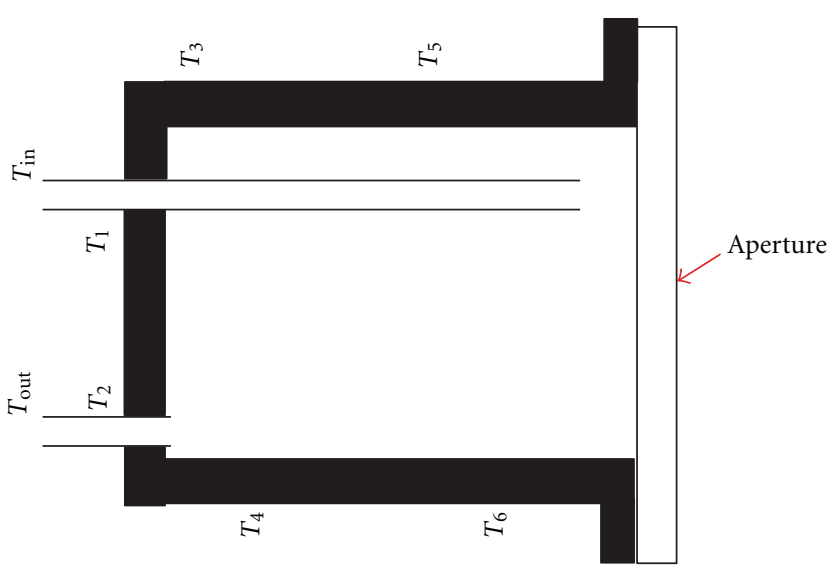

FIGURE 3: Schematic diagram of the VB receiver that also show the locations of the thermocouples.

the FR in such a way that its vertex points towards the vertex of the PDR. The advantage of a receiver with such a shape is that it occupies a good part of the FR that receives high CSR. Thus it differs from the other two designs. This cone-shaped receiver is referred to as Conical Tube (CT) receiver. Figure 4 shows the schematic diagram of the $\mathrm{CT}$ receiver.

The CT receiver consists of a copper pipe that is wound or coiled around a copper cone to form a conical coil. The coiled pipe and the cone form the absorber and hence the CSR is mainly focused onto them. The oil flows in the coiled pipe from the vertex of the cone and comes out close to the cylinder part of the receiver as shown in Figure 4. Thus the cone and the coiled pipe form the absorber for the CT receiver.

\section{Experimental Techniques}

A positive displacement pump was designed and constructed as shown in Figure 5 for pumping oil through the receivers. The pump can withstand the high operating temperatures $\left(\approx 300^{\circ} \mathrm{C}\right)$ of the receivers. It is a positive displacement pump. In developing this pump, a pump that is used in a Nissan car was modified for use with the receiver. A metal plate with two pipes attached to it was fabricated and fixed to the pump such that the two pipes formed the inlet and the outlet of the pump. An oil-resistant gasket was placed between the metal plate and the pump to prevent air suction during its operation. An inlet pipe of an oil pressure gauge was attached to the bottom of the pump so that it could be used for measuring the pressure of the oil (and hence the pressure across each pump). A motor from an electric screw driver was attached to the shaft of the pump and used to drive it. The motor of the electric screw driver requires a maximum of $12 \mathrm{~V} \mathrm{dc}$ and two cables were used to provide power to the motor. By varying the voltage supplied to the motor, the speed of the pump is varied in revolutions per second (rev/s). Thus the volume flow rate of the oil can be controlled.

In order to obtain data on the efficiency and outlet temperature of the receivers, an experimental setup was arranged that consisted of a series arrangement of a heat exchanger 


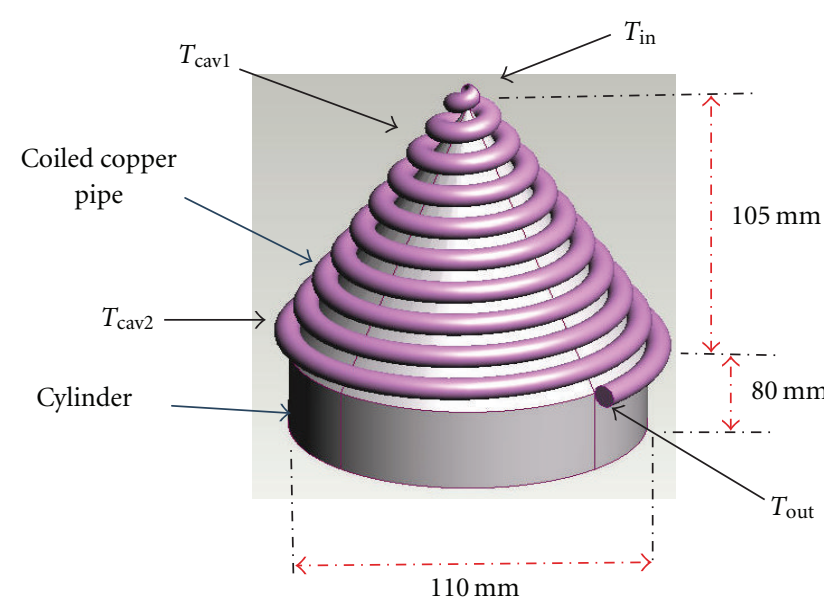

FIGURE 4: Schematic diagram of the CT receiver that also show the locations of the thermocouples.

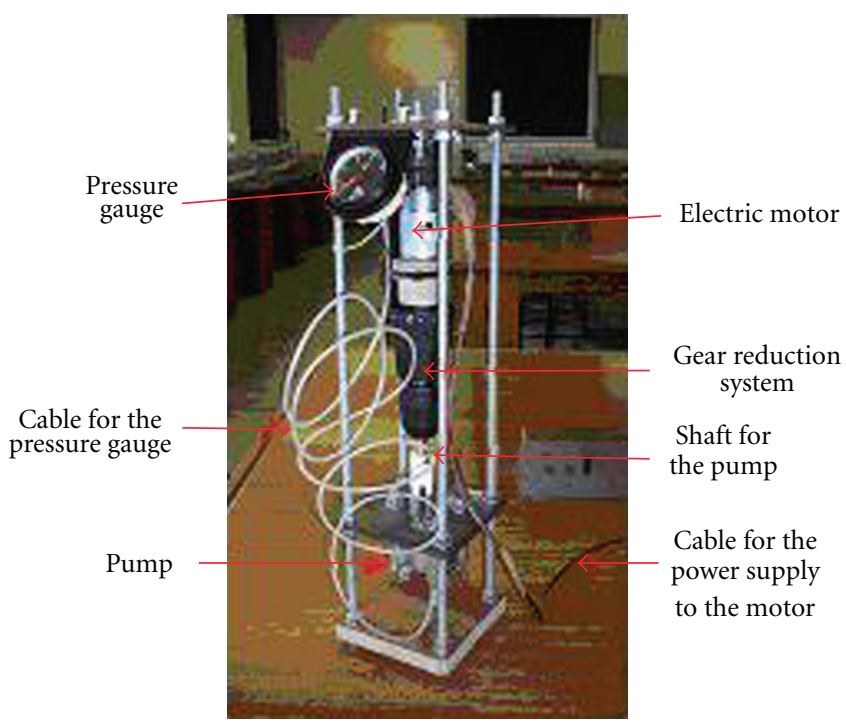

FIGURE 5: The positive displacement pump designed for high-temperature operation.

system, an oil reservoir, two identical positive displacement pumps, and an SK-14 PDR with a receiver. The setup is shown in Figure 6 and was such that oil from the reservoir was pumped through the receiver to the heat exchanger and back to the oil reservoir. The exchanger cools the heated oil from the receiver before it flows back to the reservoir. The reason for the cooling is to control the temperature of the oil in the reservoir to ambient values as the experiment was carried out throughout the day with continuous heating of the oil. It was, thus, possible to restrict the temperature of the oil flowing into the receiver to ambient values.

Figure 7 shows a circuit diagram of a debounce switch that was used to measure the speed of the pump. A small magnet is attached to the shaft of the pump and a reed switch is placed close to the shaft of the pump. The switch is temporarily closed every time the magnet passes it as the shaft rotates.

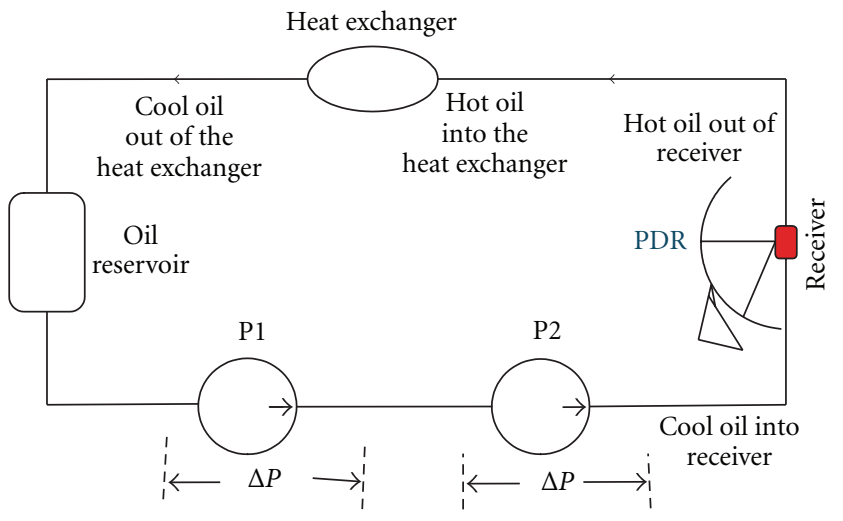

FIgURE 6: The experimental setup showing the configuration of the two positive displacement pumps, $\mathrm{P} 1$ and $\mathrm{P} 2$.

The speed of the shaft (thus of the pump) is then obtained from the total number of times that the reed switch closes in unit time. In order to improve the counting of the number of closures, a debounce circuit is connected to the reed switch, forming a debounce switch. The pumps were calibrated and found to displace an oil volume of $V=6.8 \pm$ $0.1 \mathrm{~mL} / \mathrm{rev}$ at a zero differential pressure $(\Delta P)$ across them. In calibrating the pumps, a simple and cheap method was used. The volume of oil displaced per revolution was obtained by measuring the volume of oil pumped for a certain number of revolutions of the pump when the pump pressure was zero. For each fixed number of revolutions, the measurement was repeated five times and an average was obtained. The data obtained were used to plot a graph of average volume against the number of revolutions. The slope of the graph gave the volume per revolution.

A data logger connected to a computer was used to count the number of pulses from the debounce switch over a certain interval of time to obtain the speed in rev/s. The volume flow rate is then obtained from the product of rev/s and volume (vol) per revolution obtained during calibration of the pumps.

During the initial test of the pumps, it was noted that the volume of oil displaced per revolution decreased with an increase in the pump pressure, and this is due to slippage of the pump. To overcome this problem, a configuration of two identical pumps (P1 and P2) was devised. Two pumps were connected in series as shown in Figure 6. When both pumps were switched on, the speed of P2 was set such that the differential pressure $\left(\Delta P_{1}\right)$ across $\mathrm{P} 1$ was zero. $\mathrm{P} 1$ was then used to measure the $\mathrm{vol} / \mathrm{rev}$ of the oil in the system. In this way, P1 was used as a flow meter, while P2 was used to drive the oil through the system. The volume flow rate of pump P1 was also confirmed by connecting a high-precision Macnaught $\mathrm{M}$ series flow meter (Model M1SSP) in series with the two pumps shown in Figure 6. The experiment confirming the flow rate of pump P1 was carried out with oil at room temperature up to about $120^{\circ} \mathrm{C}$, which is the maximum allowed operating temperature of the high-precision flow meter. It was observed that flow rate of pump P1 was very nearly equal to that of the high-precision 


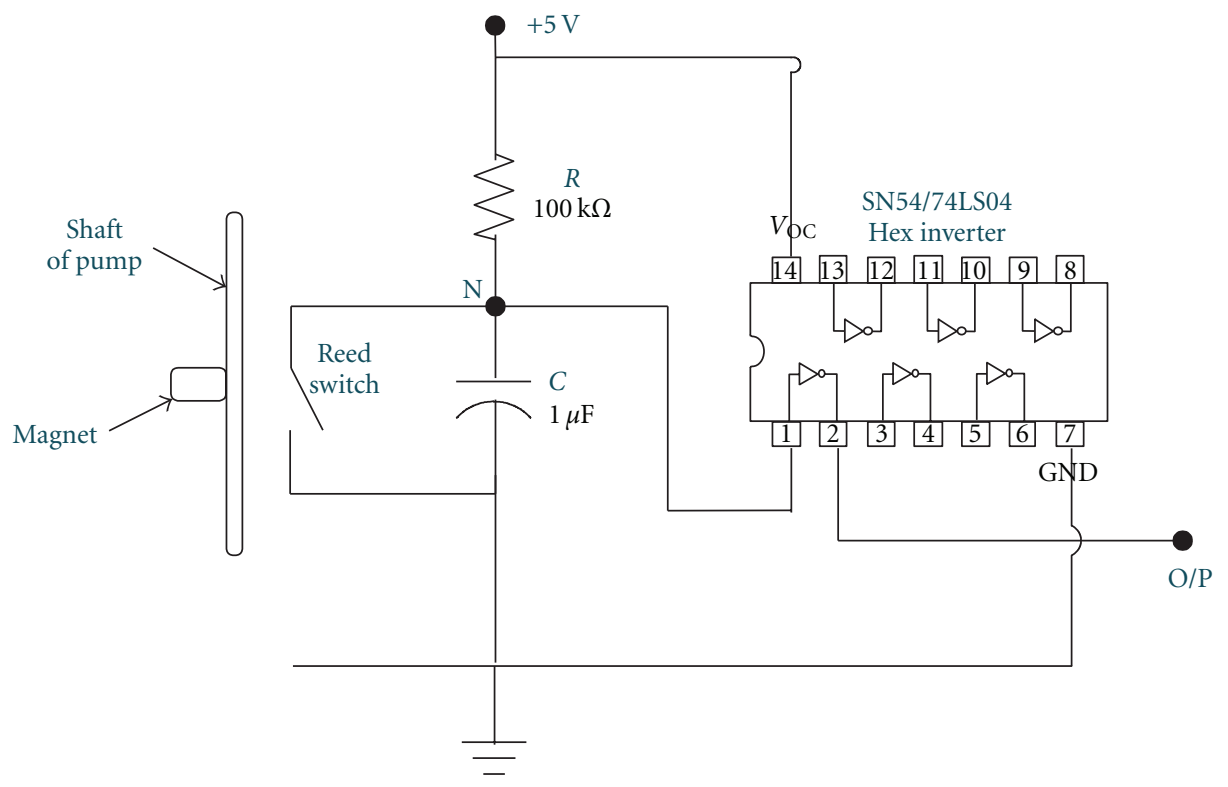

FIGURE 7: A circuit diagram of the debounce switch used to measure the speed of the shaft and so of the pump.

flow meter. Thus, a cheap and high-temperature positive displacement pump and flow meter were also designed for use in such solar thermal studies.

In order to determine the efficiency of the receivers, each one was placed at the FR of the PDR. The PDR was then placed to face towards the sun such that the rays of the direct solar radiation (DSR) were perpendicular to its aperture. In this way, the PDR was able to reflect the DSR to the receiver. The DSR was measured by means of a Normal Incidence Pyrheliometer (NIP) which was attached to a sun tracker. Thus a combination of the NIP, the data logger and the computer were used to measure, acquire, and store DSR data.

During testing of each receiver, several temperatures of the oil were measured by using K-type thermocouples placed at various points in and around the receiver. The locations of the thermocouples are shown in Figures 2, 3, and 4.

The efficiency, $\eta_{1}$, of the receiver for converting the CSR into heat energy of the oil was calculated [18] as

$$
\eta_{1}=\frac{Q_{\text {useful }}}{P_{\text {incident }}},
$$

where $P_{\text {incident }}$ is the input solar power (in the form of CSR) and $Q_{\text {useful }}$ is the heat per unit time gained by the oil while inside the receiver. $Q_{\text {useful }}$ is given by

$$
Q_{\text {useful }}=\dot{m} c_{p}\left(T_{\text {out }}-T_{\text {in }}\right)
$$

and $P_{\text {incident }}$ is given by

$$
P_{\text {incident }}=A_{\mathrm{pdr}} I_{b},
$$

where $\dot{m}$ is the mass flow rate of the oil, $c_{p}$ is the specific heat capacity of the oil at temperature $T_{\text {rec }}, A_{\text {pdr }}$ is the effective aperture area of the PDR $\left(\approx 1.5 \mathrm{~m}^{2}\right)$, and $I_{b}$ is the DSR. Here, $T_{\text {rec }}$ given by

$$
T_{\text {rec }}=\frac{\left(T_{\text {in }}+T_{\text {out }}\right)}{2}
$$

and is the temperature of the receiver, where $T_{\text {in }}$ and $T_{\text {out }}$ are the inlet and outlet temperatures of the oil.

All variables used in the calculation of the efficiencies were measured when the receiver temperatures and volume flow rate of the oil were no longer changing significantly (receivers in a steady state). Since several sets of readings were recorded for the mass flow rate, the DSR and the temperatures, their average values were recorded and their standard deviation considered as their errors. In order to reduce the uncertainty in the calculated efficiency at a particular mass flow rate, several measurements of the various variables used in calculating $\eta_{1}$ were carried out. $\eta_{1}$ was then calculated for each particular set of the variables. The average value of $\eta_{1}$ was then calculated and recorded as the efficiency while its standard deviation was taken as its error. The efficiencies of the two volumetric receivers (VF and VB) were also measured with a wire mesh inserted into them. The porosity $(\varphi)$ of the wire mesh was $\approx 0.90$. The wire mesh is stainless steel pot scourer that was spray-painted with black mat paint. The efficiency of the CT receiver was also measured when its absorber was painted with black matt paint.

\section{Results and Discussion}

The results obtained from the receivers before and after they were modified are presented. Figure 8 shows a variation of the efficiency with flow rate. The individual efficiencies for the three receivers generally increase with an increase in the flow rate, respectively. This is expected because as the flow rate is increased, more heat is carried out of the receiver and the radiative heat losses are reduced.

In Figure 8(a) the efficiency of the VF receiver shows an almost linear increase from low mass flow rates up to a flow rate of $\approx 0.001 \mathrm{~kg} / \mathrm{s}$. This suggests that radiative losses 


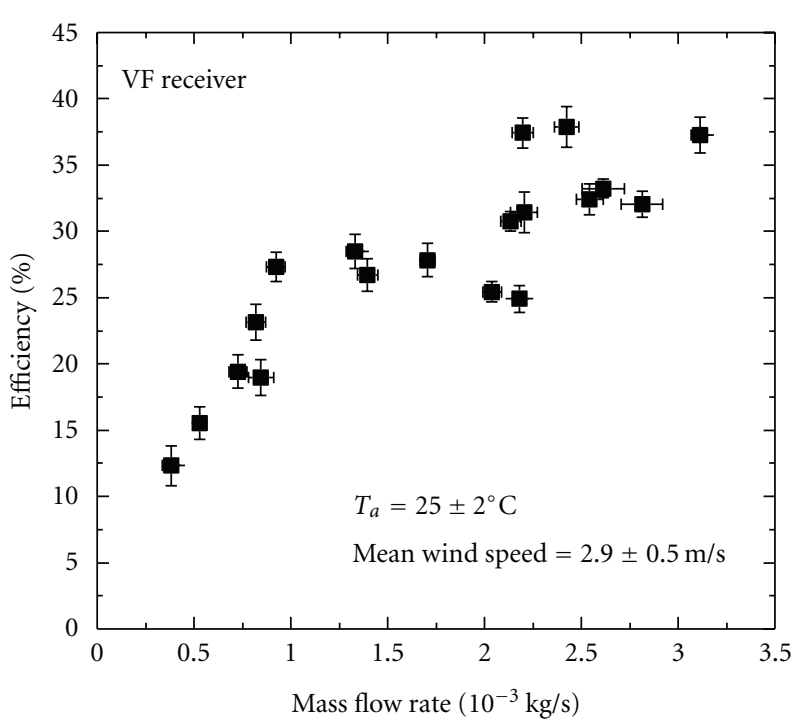

- Efficiency

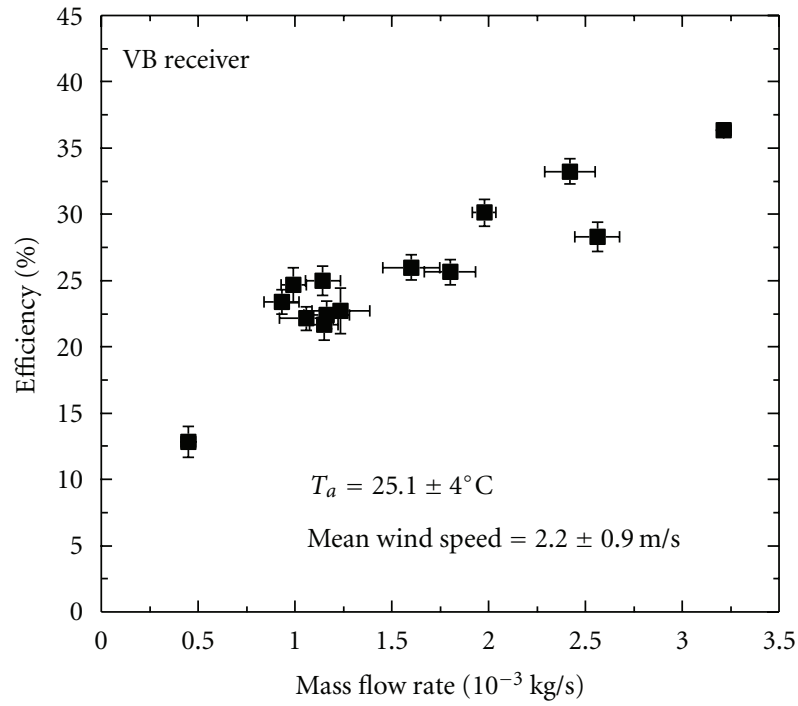

- Efficiency

(a)

(b)

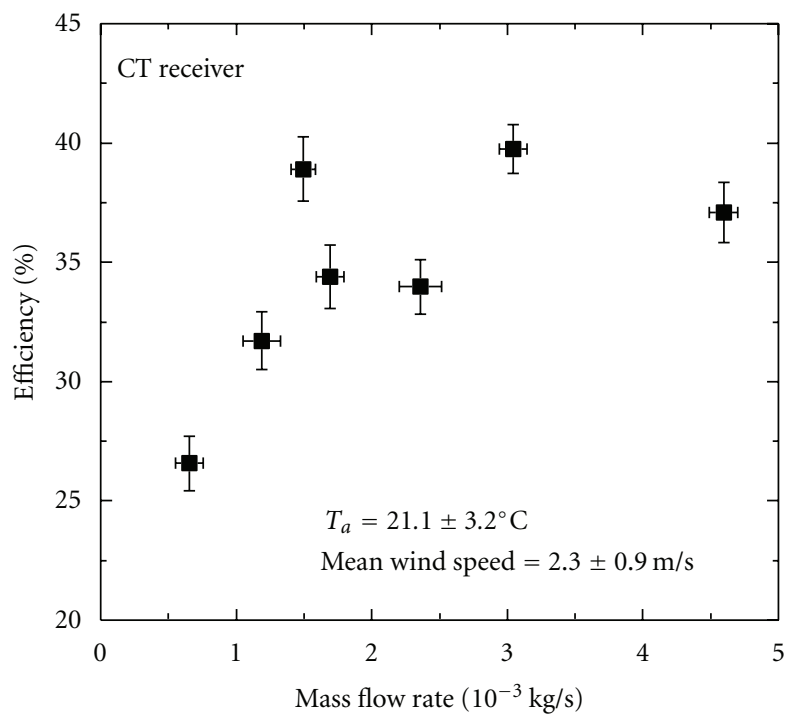

- Efficiency

(c)

FIGURE 8: A variation of the efficiency with mass flow rate for the VF (a), VB (b), and CT (c) receivers.

(due to the receiver's temperatures) have little effect on the efficiency since it does not vary according to $T_{\text {rec }}^{4}$. Figures $8(\mathrm{~b})$ and $8(\mathrm{c})$, on the other hand, show a dominant effect of the radiative losses.

Figure 9 shows the variation of $T_{\text {out }}$ of the three receivers. $T_{\text {out }} \geq 150^{\circ} \mathrm{C}$ has been found to be sufficient for cooking purposes [19]. This temperature is obtained at flow rates of $\leq 0.0015 \mathrm{~kg} / \mathrm{s}$ for the VF and VB receivers. Hence these flow rates of these two receivers are sufficient to charge a TES that can be used for cooking purposes. $T_{\text {out }} \geq 150^{\circ} \mathrm{C}$ is achieved by the CT receiver for mass flow rates of $\leq 0.002 \mathrm{~kg} / \mathrm{s}$. Measurements of $\eta_{1}$ and $T_{\text {out }}$ for mass flow rates greater than $\approx 0.0035 \mathrm{~kg} / \mathrm{s}$ were not carried out as $T_{\text {out }}$ dropped below $100^{\circ} \mathrm{C}$ and temperatures below $100^{\circ} \mathrm{C}$ are not sufficient for either cooking purpose or charging a TES that can be used for cooking.

In Figure 9(a), $T_{\text {out }}$ of the VF receiver approximately varies linearly with the mass flow rate and this is because of the reduced influence of radiative losses. This reduced effect is mainly due to its design which allows the CSR to be incident on a larger (parabolic) surface area of the aperture and the inlet which is close to the aperture (Figure 2). The Figures 9(b) and 9(c) show that their $T_{\text {out }}$ is strongly influenced by radiative losses. 


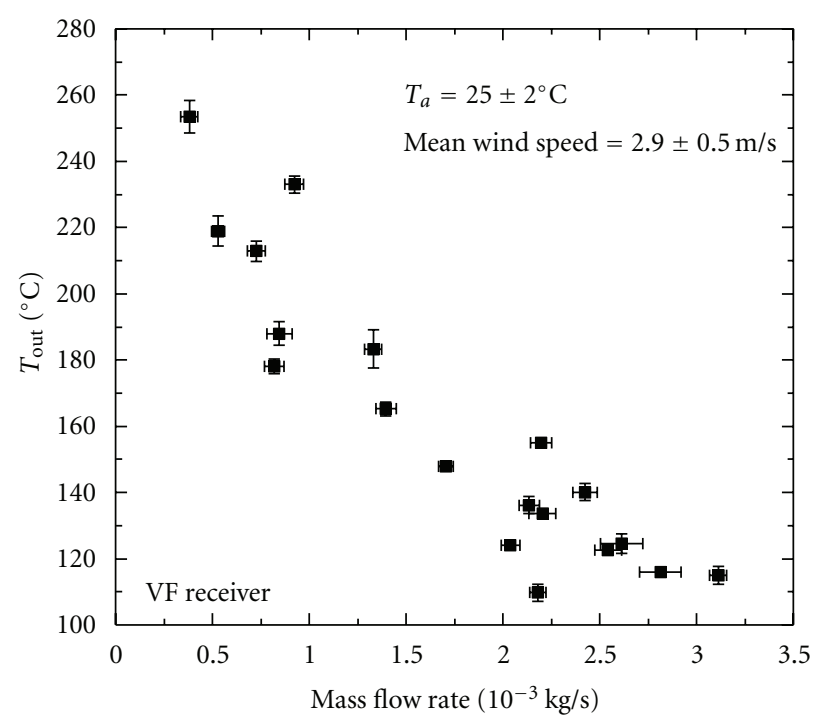

- $T_{\text {out }}$

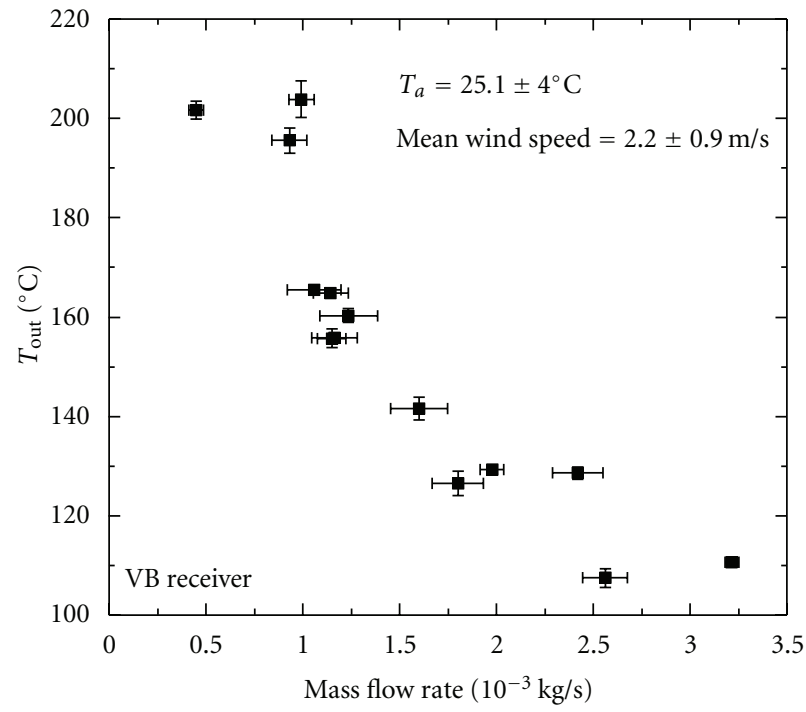

- $T_{\text {out }}$

(b)

(a)

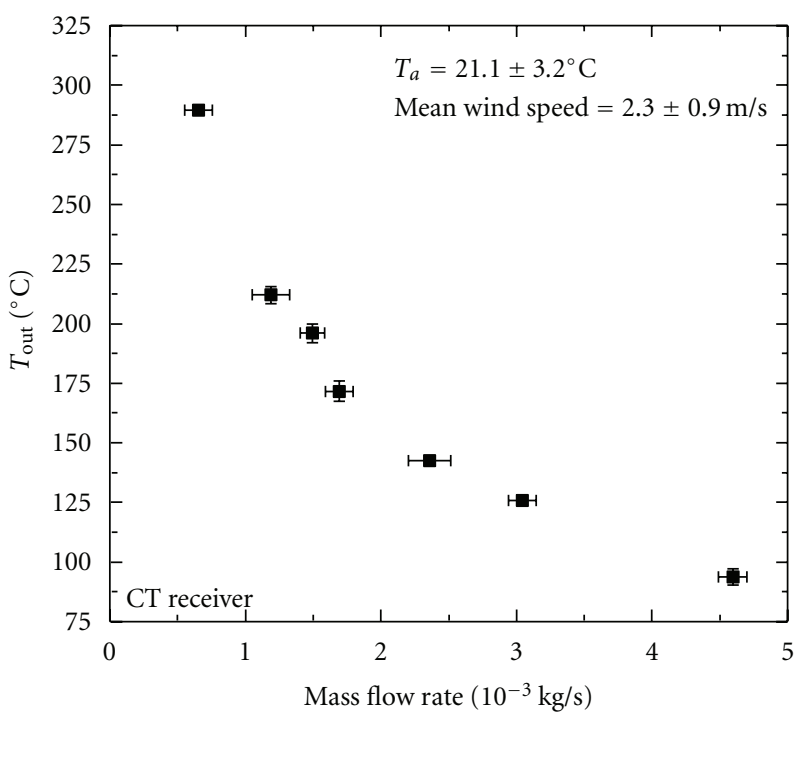

(c)

FIGURE 9: A variation of $T_{\text {out }}$ with mass flow rate for the VF (a), VB (b), and CT (c) receivers.

Figure 10 shows plots of all the temperatures measured on and inside the receivers. Figure 10(a) shows temperatures measured inside and on the VF receiver as depicted in Figure 2. $T_{1}$ is higher than $T_{2}$ for all mass flow rates and this is because the inlet pipe is positioned close to the aperture and the oil flowing from the inlet cools the aperture. The temperatures $T_{3}, T_{4}, T_{5}$, and $T_{6}$ are measured on the reflecting plate and are much higher than $T_{1}, T_{2}$, and $T_{\text {out }}$ at large flow rates. This shows that the temperatures on the reflecting plate are not strongly affected by the flow rate of the oil and this is because the reflecting plate is covered with an aluminium foil on the side in contact with the glass flask and is heavily insulated with glass wool on the other side. The function of the aluminium foil is to increase the reflection of the CSR and hence reduce the temperature of the reflecting plate. $T_{4}$ is relatively higher than the rest of the other temperatures. This is because the aluminium foil, where the thermocouple was placed, melted during the experiment and so reduced the amount of the CSR that was reflected. This resulted in an increased plate temperature.

Figure 10 (b) shows the variation of the temperatures on the VB receiver as shown in Figure 3. $T_{6}$ is the highest temperature recorded followed by $T_{5}$. Both $T_{5}$ and $T_{6}$ are 


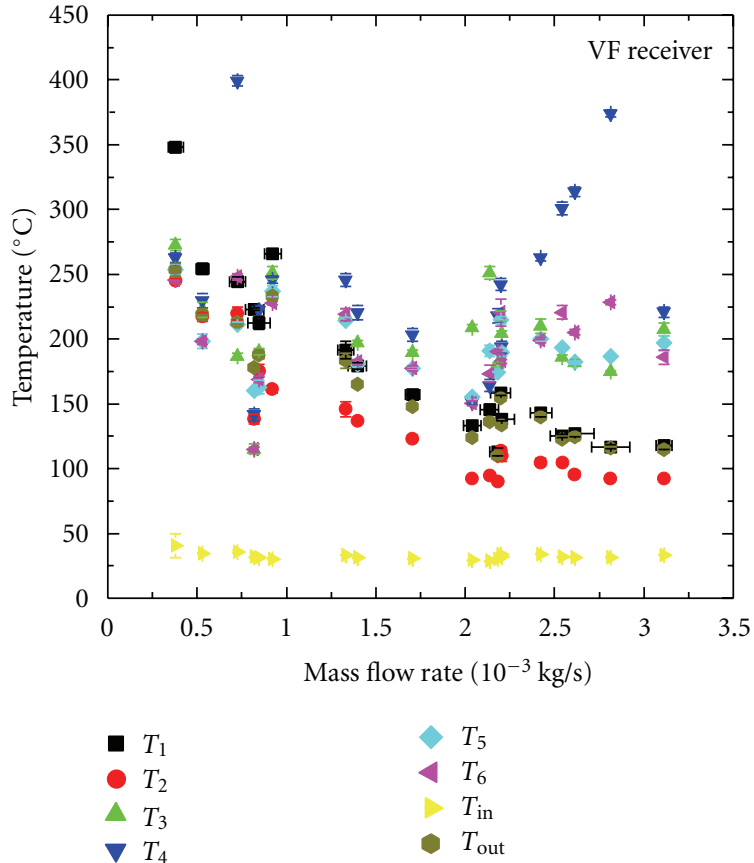

(a)

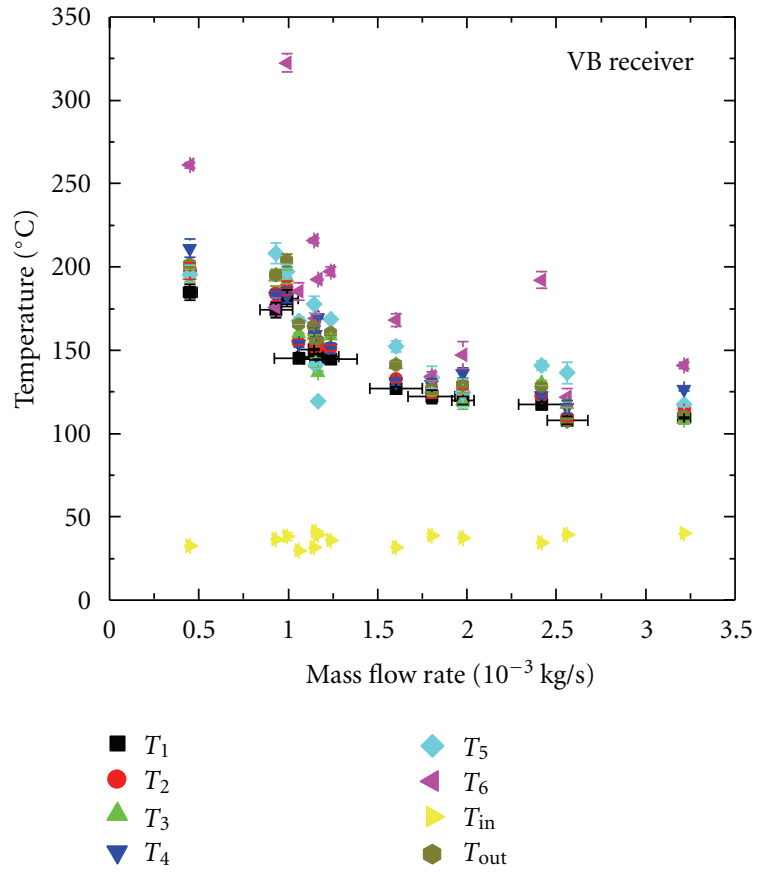

(b)

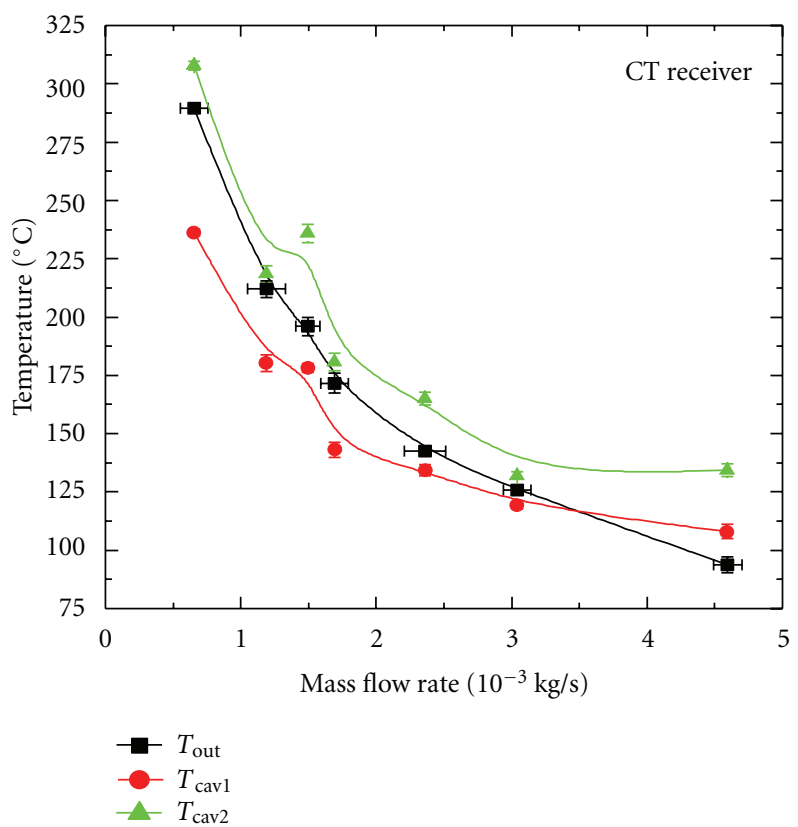

(c)

FIgURE 10: A variation of the various temperatures measured on the receivers with mass flow rate.

temperatures measured close to the cylindrical part of the $\mathrm{VB}$ receiver that was not insulated and received CSR. Apart from this, the rest of the temperatures on the receiver are very close to each other and $T_{\text {out }}$ is not significantly different from these temperatures. The implication is that the cylindrical part of the VB receiver not insulated presents a region where the oil may be degraded due to high temperatures that are higher than its maximum film temperature of $340^{\circ} \mathrm{C}$ [20]. Because
$T_{\text {out }}$ is nearly equal to most of the temperatures recorded on the receiver, the VB receiver should always be well insulated for better performance.

In Figure 10(c), $T_{\mathrm{cav1}}$ was measured at the cone vertex and $T_{\text {cav2 }}$ is the cone temperature close to the cylindrical part of the receiver where the outlet is located (Figure 4). $T_{\text {cav2 }}$ is always higher than $T_{\text {cav1 }}$ because there is a higher flux concentration close to the $\mathrm{CT}$ receiver outlet as compared to 


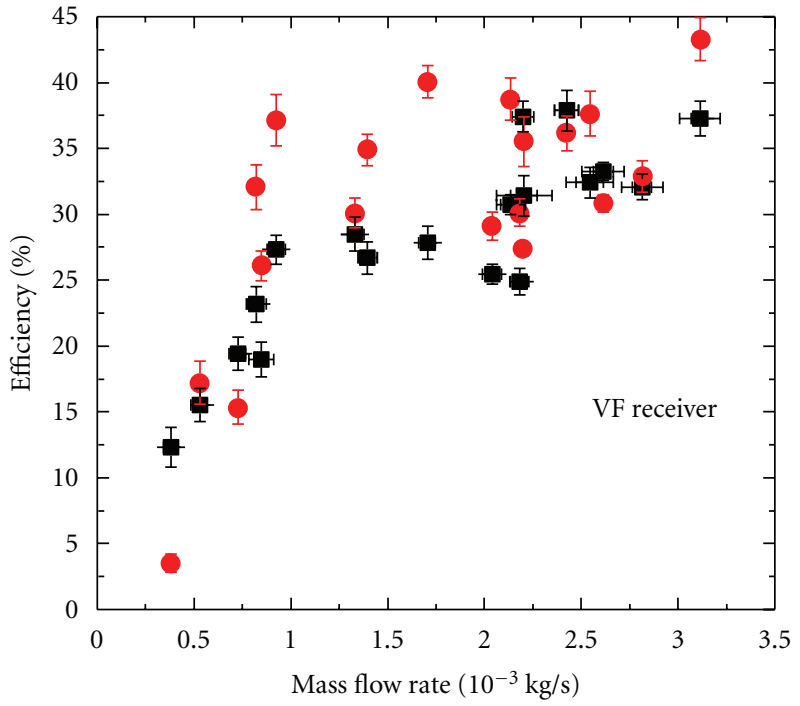

- Without mesh wire

- With mesh wire

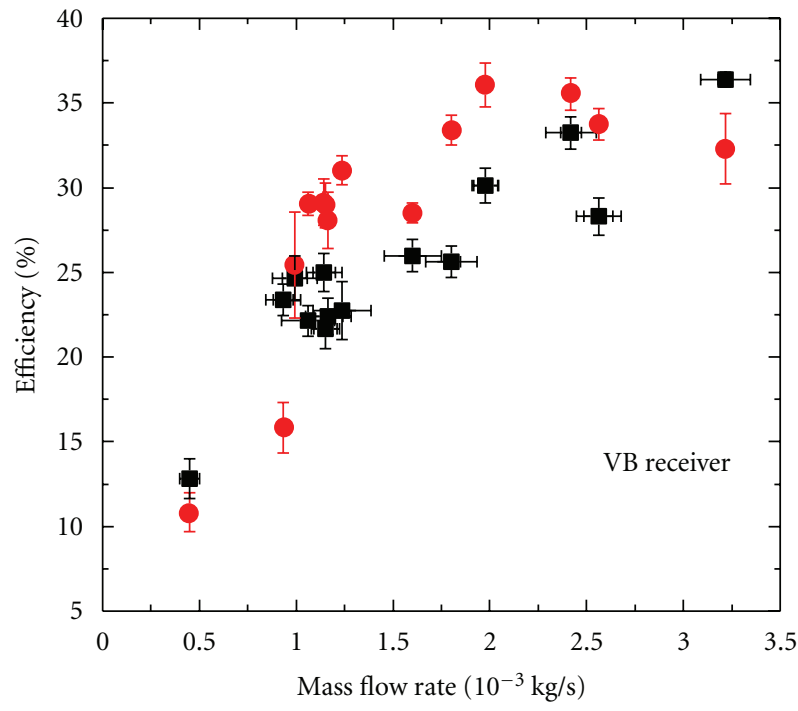

- Without mesh wire

- With mesh wire

(a)

(b)

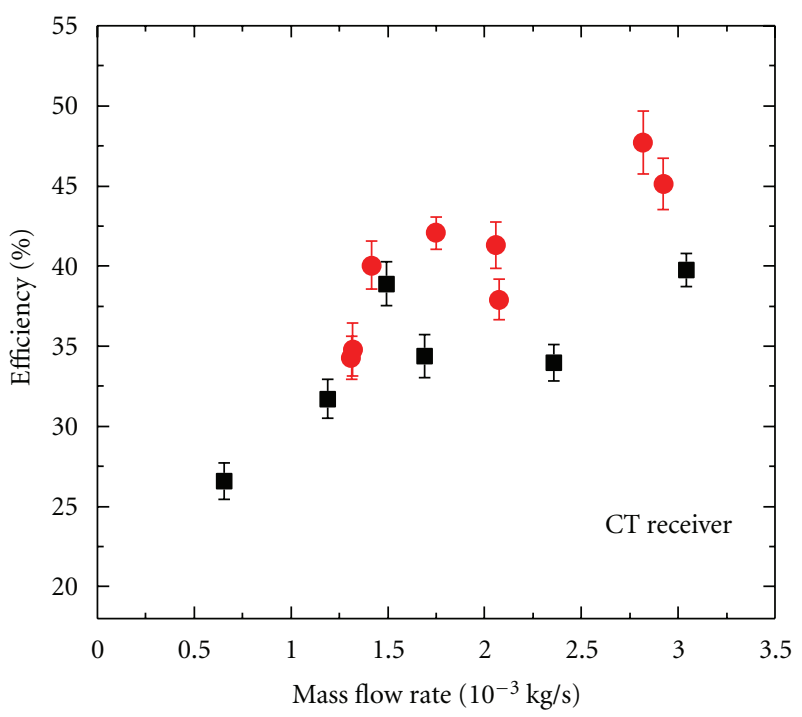

- Unpainted receiver

- Painted receiver

(c)

FIGURE 11: Comparison of the efficiencies for the receivers before and after modification.

the receiver inlet. Increase in the flux concentration implies increase in the CSR. The difference is also because the CT receiver inlet of the coiled pipe is located at the vertex of the cone and hence the cool oil flowing from the inlet cools it down.

Thus for the CT receiver, the specific heat capacity $(\mathrm{J} / \mathrm{K} \mathrm{kg})$ of the Shell Thermia B oil used in the experiment increases with increase in the oil temperature is. Thus the higher the oil temperature, the higher the CSR required to increase the oil temperature by a unit must be. The fact that the inlet is located at the vertex of the cone where there are low levels of CSR and that the outlet is located where there are high levels of CSR is an advantage. This is because the cool oil (with less specific heat capacity) from the inlet is exposed to low CSR levels and the CSR levels increase as the oil temperature increases (increase in the specific heat capacity of the oil). Hence the receiver design enables a gradual increase in the CSR as the temperature of the oil in the absorber increases and this enables attainment of high $T_{\text {out }}$ for a given flow rate. 


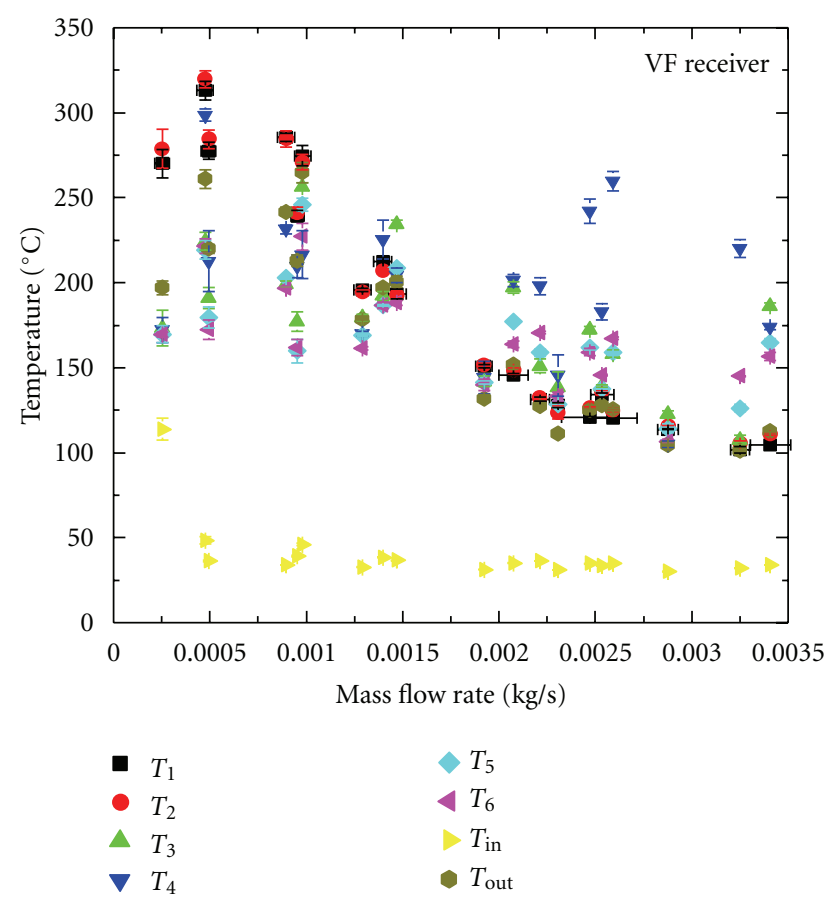

(a)

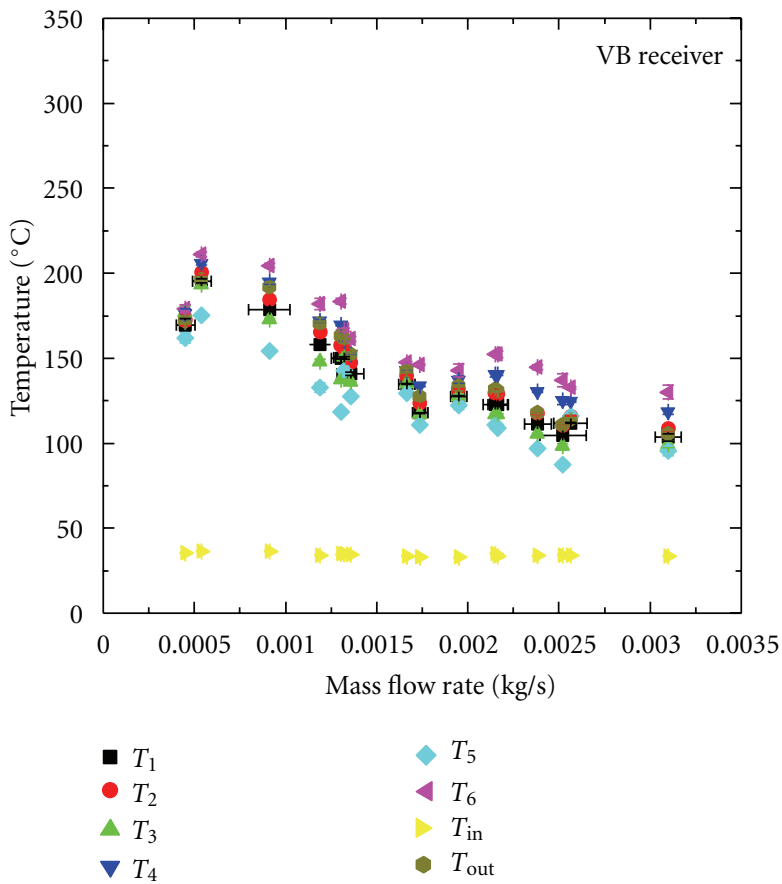

(b)

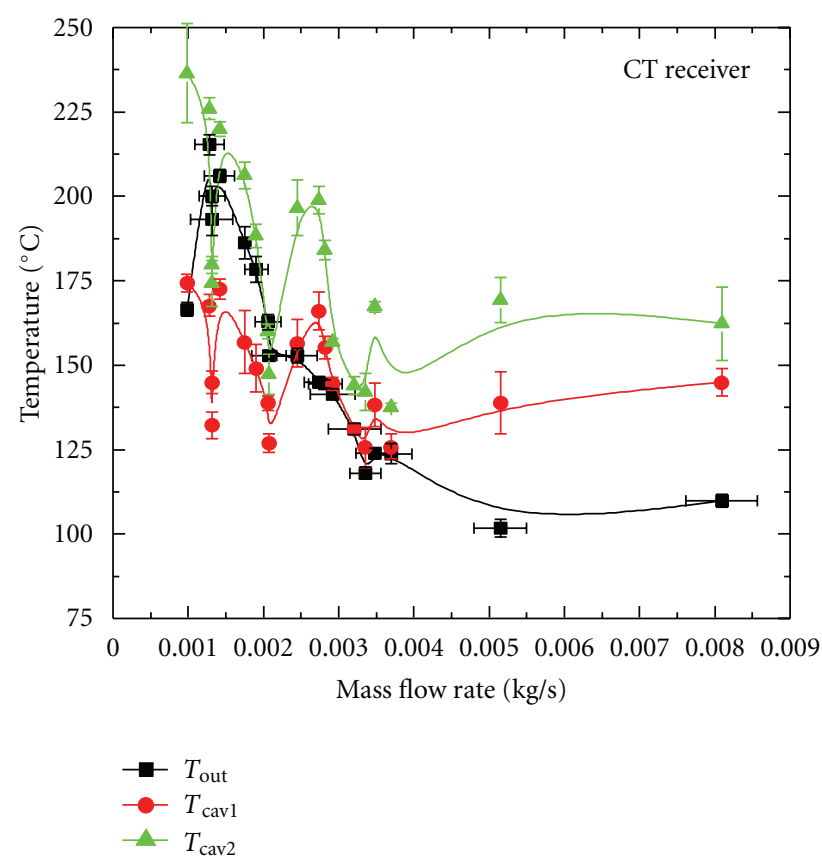

(c)

FIGURE 12: The variation of the temperatures on the modified receivers.

$T_{\text {out }}$ is close to $T_{\text {cav2 }}$ for the CT receiver and it is less than $T_{\text {cavl }}$ for very high flow rates. For the rest of the other flow rates, $T_{\text {out }}$ is always between $T_{\text {cav1 }}$ and $T_{\text {cav2 } 2}$. For low flow rates, the oil in the coiled pipe (part of the absorber) has a high retention time that it is able to absorb enough heat to attain temperatures close to that of $T_{\text {cav2 }}$. For high flow rates, $T_{\text {out }}$ is less than $T_{\text {cavl }}$ because the oil flowing in the absorber has less retention time and hence absorbs less heat from the absorber.

The performance of the receivers was also evaluated when the receivers were modified and Figure 11 shows a comparison of their efficiencies before and after modification. Figures 11(a) and 11(b) of the figure show that the efficiencies of the VF and VB receivers containing a wire mesh are slightly 

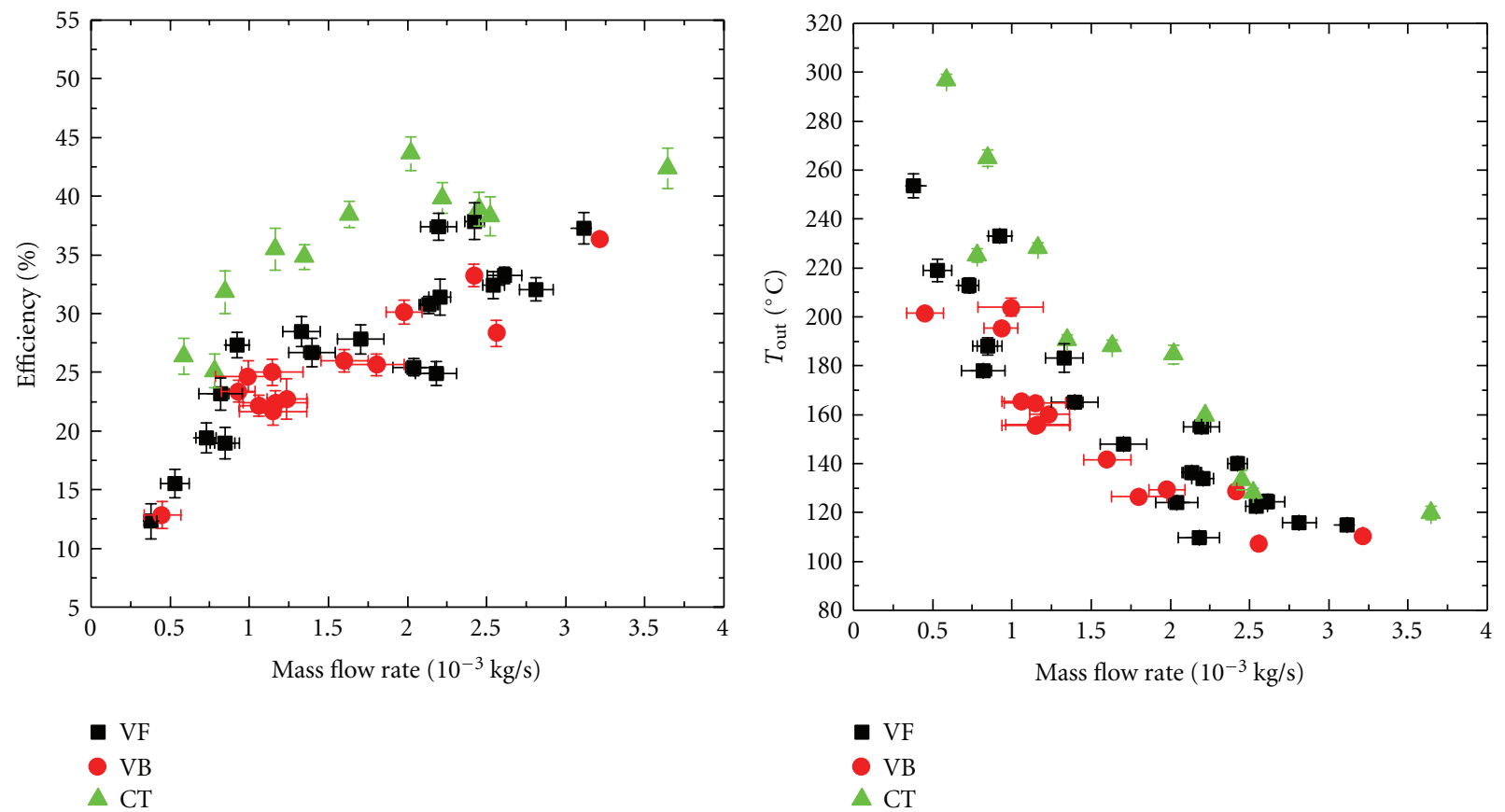

(a)

(b)

FIGURE 13: A comparison of the efficiencies (a) and $T_{\text {out }}(\mathrm{b})$ of the VF and VB receivers with no wire mesh and the CT receiver not painted.

higher than when they do not contain a wire mesh. This is because the wire mesh increases the solid-fluid interface area and hence increases the absorption of the heat by the oil. The wire mesh also increases the effective thermal conductivity of oil/wire mesh combination and the mixing of the oil within the receiver. In Figure 11(c), the efficiency for the painted CT receiver is slightly higher than that of the unpainted CT receiver and this is due to the increased absorption of the incident CSR by the absorber (that is made up of cone and the coiled pipe). The significant scattering of measurements after the receiver were modified is because the measurements were carried out during very windy days.

The effect of the wire mesh on $T_{\text {out }}$ and the other temperatures measured on and inside the VF and VB receivers is shown in Figures 12(a) and 12(b). $T_{\text {out }}$ and all the temperatures measured on and inside the volumetric receivers are very close to each other and this is because of the increased effective thermal conductivity introduced by the wire mesh. In fact, $T_{\text {out }}$ is approximately an average of the receiver temperatures. For the VF receiver, $T_{4}$, that is measured on the reflecting plate, has been substantially reduced compared to when the receiver does not contain a wire mesh.

In Figure 12(c), the stagnation temperature ( $T_{\text {out }}$ at low flow rate) for the painted CT receiver is lower than that for the unpainted CT receiver. This is because the black paint increases the absorption of the incident CSR by the coiled pipe (where the oil flows) and the cone and hence reduces the reflected CSR. Thus the paint reduces the amount of CSR that is reflected by the cone to the coiled pipe and this in turn reduces the stagnation temperature of the receiver. This implies that part of the CT receiver absorber that should be painted black is the coiled pipe and the cone should not be painted so that it reflects most of incident CSR to the coiled pipe. This would be advantageous as most of the CSR absorbed by the cone is lost through conduction, convection, and reradiation. The other reason is that the black matt paint has a higher emissivity compared to copper and hence it increases the radiation losses at lower flow rates.

Thus the painted CT receiver has a slightly higher efficiency for a given mass flow rate than an unpainted CT receiver, but with a penalty of reduced stagnation temperature. Thus when coating the absorber of the CT receiver with paint of high absorptance, the coiled pipe should be the only part painted so that the cone can reflect most of the incident CSR to the coiled pipe.

The experimental performances of the three receivers have been compared and plot Figure 13(a) shows the efficiencies of the volumetric receivers without the wire mesh and that of the unpainted CT receiver. The figure indicates that the $\mathrm{CT}$ receiver has the highest efficiency. The $\mathrm{CT}$ receiver has a maximum efficiency of $\approx 42 \%$ for a flow rate of $\approx 0.003 \mathrm{~kg} / \mathrm{s}$, while that of the VF and VB receivers is $\approx 35 \%$ for the same flow rate. The efficiency of the VF and VB receivers are almost equal for all flow rates. Figure 13(b) shows that $T_{\text {out }}$ of the CT receiver is higher than that of the VF and VB receivers. $T_{\text {out }}$ of the VF receiver is equal, within the experimental accuracy, to that of the VB receiver for most of the flow rates.

The performances of the three receivers were also compared after they were modified and the painted CT receiver has the highest efficiency whereas the VF and VB receivers have efficiencies that are close. The maximum efficiency of the $\mathrm{CT}$ receiver is $\approx 45 \%$ while those of the $\mathrm{VF}$ and $\mathrm{VB}$ receivers are $\approx 40 \%$. $T_{\text {out }}$ of the painted CT receiver is higher than those of the volumetric receivers containing a wire mesh. 


\section{Conclusions}

The results indicate that inserting a wire mesh into the volumetric receivers (VF and VB) increases their efficiency. The receiver temperatures with a wire mesh inserted into the two receivers are nearly equal to indicate a more uniform distribution of heat. Such receivers should thus be operated with a wire mesh to improve their performance.

The results also show that painting the absorber of the CT receiver improves its efficiency. However, this also reduces stagnation temperature. This is because when the absorber, comprising the cone and the coiled pipe, is not painted, the cone reflects part of the incident CSR to the coiled pipe and this result in a higher stagnation temperature. Thus when painting the absorber of the CT receiver, only the coiled pipe should be painted black so that the cone can reflect some of the CSR to the coiled pipe. The results also show that, because of its overall performance, the CT receiver is a better design to use with an SK-14 PDR than the volumetric receivers. In the experimental testing of the receivers, a low-cost and hightemperature positive displacement pump and a flow meter have been designed and fabricated for use in solar thermal studies.

\section{Nomenclature}

\begin{tabular}{|c|c|}
\hline$\dot{m}:$ & Mass flow rate of oil $\left(\mathrm{kg} \mathrm{s}^{-1}\right)$ \\
\hline$\varphi:$ & Porosity of a porous medium \\
\hline$\Delta:$ & Change in \\
\hline$\eta_{1}:$ & $\begin{array}{l}\text { Efficiency of the receiver for converting the } \\
\text { concentrated solar radiation (CSR) into heat } \\
\text { energy of the oil }\end{array}$ \\
\hline$A_{\mathrm{pdr}}:$ & $\begin{array}{l}\text { Aperture area of a parabolic dish reflector } \\
\left(\mathrm{m}^{2}\right)\end{array}$ \\
\hline$c_{p}:$ & $\begin{array}{l}\text { Specific heat capacity at constant pressure } \\
\left(\mathrm{J} \mathrm{kg}^{-1} \mathrm{~K}^{-1}\right)\end{array}$ \\
\hline$I_{b}:$ & Direct solar radiation $\left(\mathrm{Wm}^{-2}\right)$ \\
\hline$P:$ & Pressure $\left(\mathrm{Nm}^{-2}\right)$ \\
\hline$P_{\text {incident }}:$ & $\begin{array}{l}\text { Input solar power (in the form of CSR) } \\
\left(\mathrm{Wm}^{-2}\right)\end{array}$ \\
\hline Quseful: & $\begin{array}{l}\text { Heat per unit time gained by the oil while it is } \\
\text { inside the receiver }(\mathrm{W})\end{array}$ \\
\hline$T_{\text {in }}:$ & Temperature of oil flowing into a receiver $\left({ }^{\circ} \mathrm{C}\right)$ \\
\hline$T_{\text {out }}:$ & $\begin{array}{l}\text { Temperature of the oil flowing out of a } \\
\text { receiver }\left({ }^{\circ} \mathrm{C}\right)\end{array}$ \\
\hline$T_{\text {rec }}:$ & Operating temperature of an receiver $\left({ }^{\circ} \mathrm{C}\right)$. \\
\hline
\end{tabular}

\section{Subscripts}

$\begin{array}{ll}\text { 1: } & \text { First } \\ b: & \text { Beam/direct } \\ \text { in: } & \text { Inlet } \\ \text { incident: } & \text { Incident } \\ \text { out: } & \text { Outlet } \\ p: & \text { Constant pressure } \\ \text { pdr: } & \text { Parabolic dish reflector } \\ \text { rec: } & \text { Receiver } \\ \text { useful: } & \text { Gained. }\end{array}$

\section{Abbreviations}

CSR: Concentrated solar radiation

CT: Conical tube

DSR: Direct solar radiation

FR: Focal region

HTF: Heat transfer fluid

NIP: Normal Incidence Pyrheliometer

PDR: Parabolic dish reflector

TES: Thermal energy storage

VB: Volumetric box

VF: Volumetric flask.

\section{Acknowledgments}

The author is grateful to the University of Malawi for granting a study leave and the DAAD for a studentship.

\section{References}

[1] P. O. Jarvinen, "Heat mirrored solar energy receivers," Journal of Energy, vol. 2, no. 2, pp. 95-99, 1978.

[2] R. Pitz-Paal, B. Hoffschmidt, M. Böhmer, and M. Becker, "Experimental and numerical evaluation of the performance and flow stability of different types of open volumetric absorbers under non-homogeneous irradiation," Solar Energy, vol. 60, no. 3-4, pp. 135-150, 1997.

[3] A. Kribus, P. Doron, R. Rubin et al., "A multistage solar receiver: the route to high temperature," Solar Energy, vol. 67, no. 1-3, pp. 3-11, 1999.

[4] A. Yogev and M. Wolfson, "A window for central solar receiver with volumetric absorber, World Intellectual Property Organisation," International Publication number WO 96/12918, 1996.

[5] R. Buck, C. Barth, M. Eck, and W. D. Steinmann, "Dual-receiver concept for solar towers," Solar Energy, vol. 80, no. 10, pp. 1249-1254, 2006.

[6] A. M. Clausing, "An analysis of convective losses from cavity solar central receivers," Solar Energy, vol. 27, no. 4, pp. 295300, 1981.

[7] M. Prakash, S. B. Kedare, and J. K. Nayak, "Investigations on heat losses from a solar cavity receiver," Solar Energy, vol. 83, no. 2, pp. 157-170, 2009.

[8] M. Becker, S. Cordes, and M. Böhmer, "The development of open volumetric receivers," in Proceedings of the 6th Symposium on Solar Thermal Concentrating Technologies, vol. 2, pp. 945-952, CIEMAT, Madrid, Spain, 1992.

[9] M. Böhmer and C. Chaza, "The ceramic foil volumetric receiver," Solar Energy Materials, vol. 24, no. 1-4, pp. 182-191, 1991.

[10] P. Heller, M. Pfänder, T. Denk et al., "Test and evaluation of a solar powered gas turbine system," Solar Energy, vol. 80, no. 10 , pp. $1225-1230,2006$.

[11] P. Stobbe and B. Hoffshmidt, "Hybrid volumetric receiver assembly and process for producing such assembly," International publication number WO 03/021160 A1, World Intellectual Property Organisation, 2003.

[12] K. Boomsma, D. Poulikakos, and F. Zwick, "Metal foams as compact high performance heat exchangers," Mechanics of Materials, vol. 35, no. 12, pp. 1161-1176, 2003. 
[13] T. Fend, R. Pitz-Paal, O. Reutter, J. O. Bauer, and B. Hoffschmidt, "Two novel high-porosity materials as volumetric receivers for concentrated solar radiation," Solar Energy Materials and Solar Cells, vol. 84, no. 1-4, pp. 291-304, 2004.

[14] A. Mawire and M. McPherson, "Experimental characterisation of a thermal energy storage system using temperature and power controlled charging," Renewable Energy, vol. 33, no. 4, pp. 682-693, 2008.

[15] A. Mawire, M. McPherson, R. R. J. van den Heetkamp, and S. J. P. Mlatho, "Simulated performance of storage materials for pebble bed thermal energy storage (TES) systems," Applied Energy, vol. 86, no. 7-8, pp. 1246-1252, 2009.

[16] J. S. P. Mlatho, M. McPherson, A. Mawire, and R. J. J. Van den Heetkamp, "Determination of the spatial extent of the focal point of a parabolic dish reflector using a red laser diode," Renewable Energy, vol. 35, no. 9, pp. 1982-1990, 2010.

[17] J. S. P. Mlatho, Optimisation of a parabolic solar concentrator (PSC) for use with a thermal energy storage (TES) system, Ph.D. thesis, North-West University, South Africa, 2009.

[18] H. Hasuike, Y. Yoshizawa, A. Suzuki, and Y. Tamaura, "Study on design of molten salt solar receivers for beam-down solar concentrator," Solar Energy, vol. 80, no. 10, pp. 1255-1262, 2006.

[19] R. M. Muthusivagami, R. Velraj, and R. Sethumadhavan, "Solar cookers with and without thermal storage-a review," Renewable and Sustainable Energy Reviews, vol. 14, no. 2, pp. 691-701, 2010.

[20] Shell, "Shell Thermia oil B-High performance heat transfer fluid," 2007, http://www.epc.shell.com/Docs/GPCDOC_X_ cbe_24855_key_140002282412_1C93.pdf. 

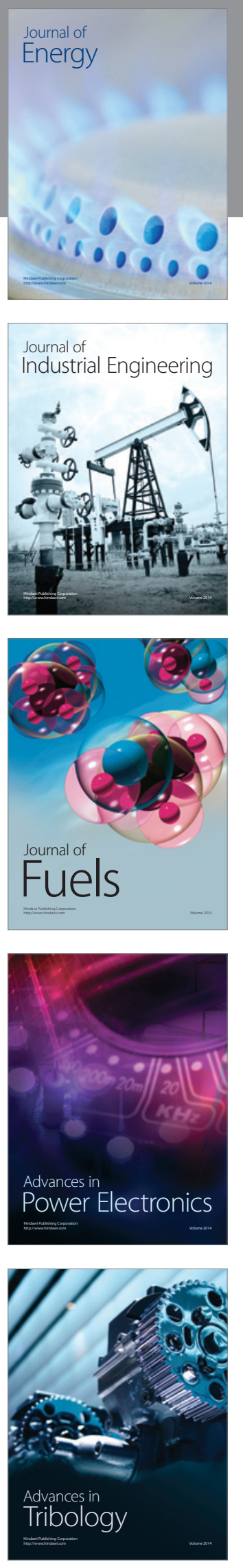
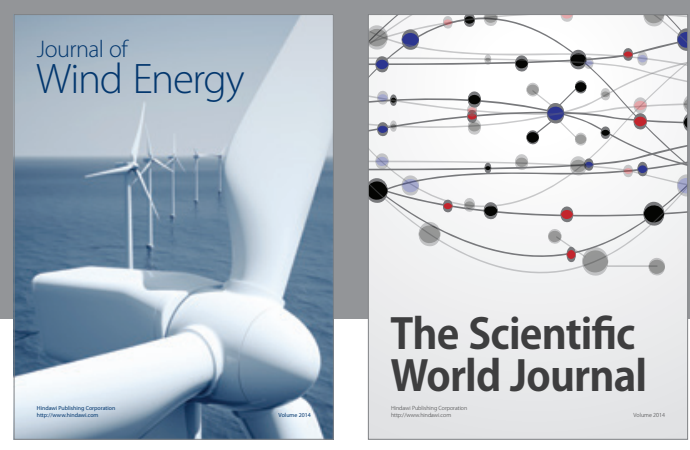

The Scientific World Journal

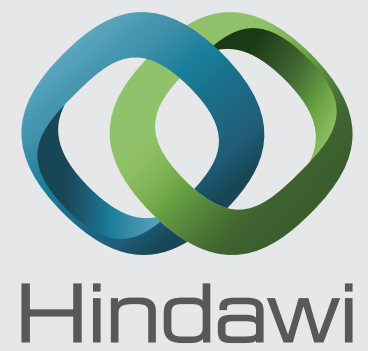

Submit your manuscripts at http://www.hindawi.com
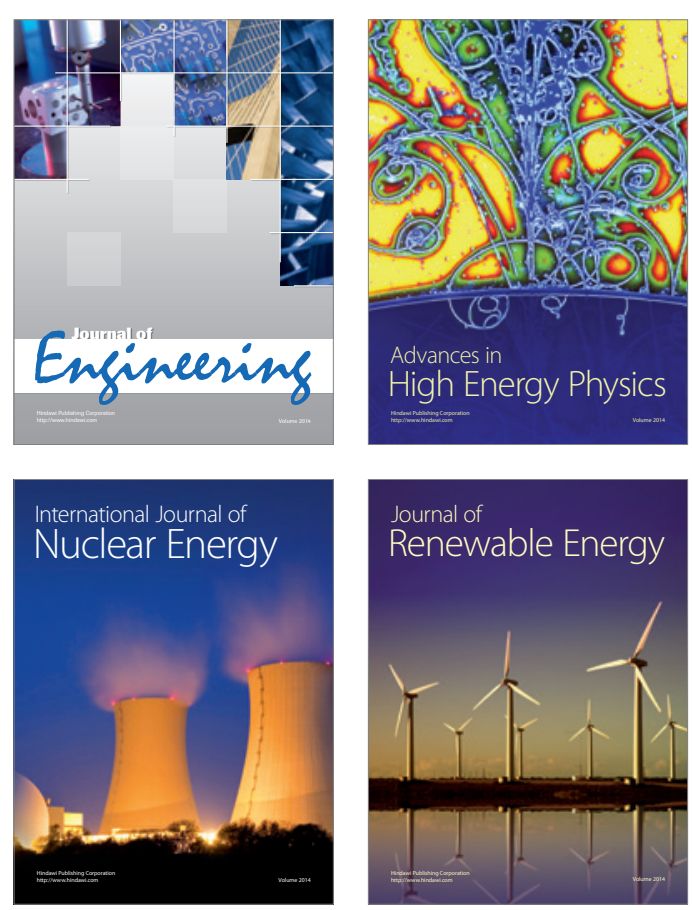

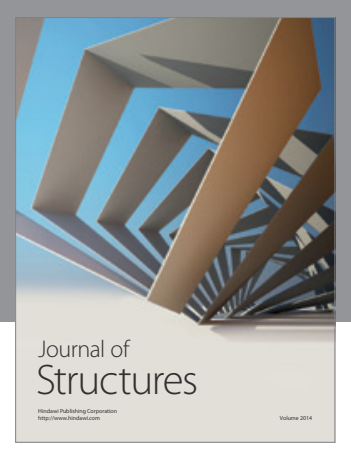

Rotating
Mechinery
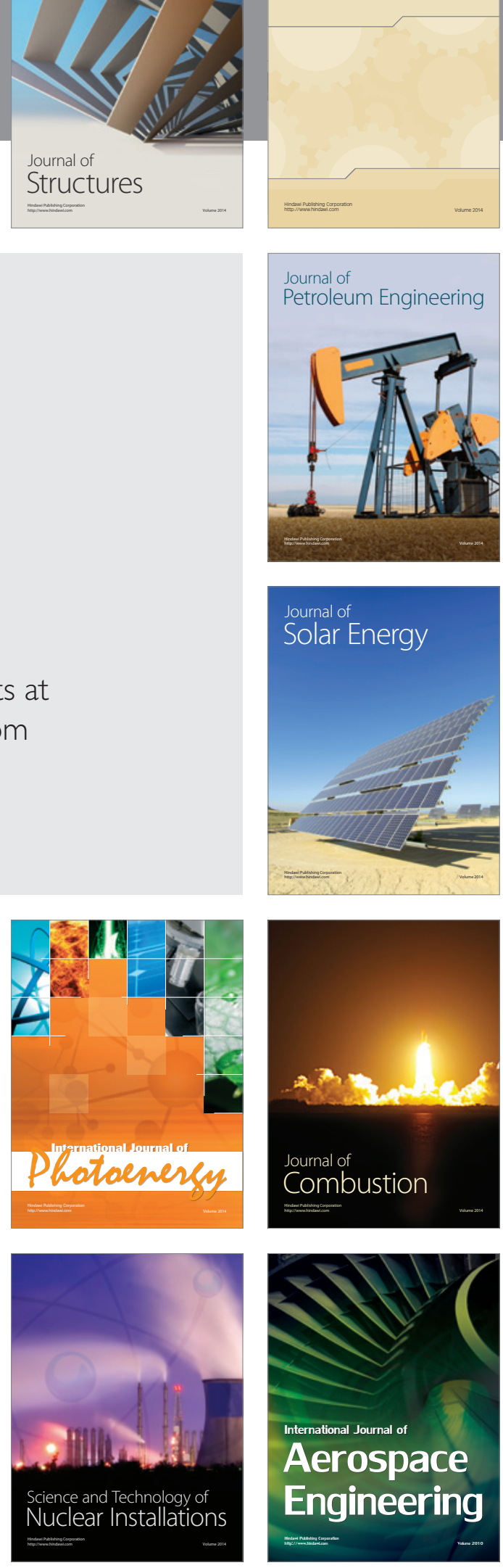